\title{
The Analysis of Lightning Protection Parameter for IDC Rooms
}

\author{
Xiangke $\mathrm{Liu}^{1, \mathrm{a}^{*}}$ and Xianfeng $\mathrm{Hu}^{1, \mathrm{~b}}$ \\ ${ }^{1}$ Lightning Protection Technology Center of Shandong Province, Jinan

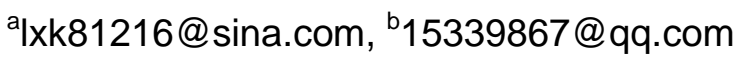

Keywords: IDC rooms; Space shielding; Cable shielding; Induced voltage

\begin{abstract}
IDC (Internet data Center), IDC is a standardized and professional computer room environment established by telecom departments using the existing Internet communication wires and bandwidth resources. IDC provides server hosting, leasing and related value-added full-service for the enterprise and the government. This paper analyzed and obtained the key parameters which Influence on the reliability of the lightning protection system reliability of IDC rooms. The key parameters include the space shielding effectiveness and the transmission cable shielding effectiveness, the maximum pulse voltage limits for terminals, the induced voltage of the biggest split ring of IDC room cabling, the voltage balancing and the discharge capacity, etc. On this basis, the key parameters are calculated through the inductive description and the method of quantitative analysis to effectively reduce the lightning stroke risk of IDC rooms.
\end{abstract}

\section{Introduction}

IDC is a hosting site of server group for government departments, enterprises, businesses, or web sites.IDC is the infrastructure for various mode of e-commerce and also the value chain management platform for enterprises and their business alliances distributors, suppliers, customers, etc [1]. If IDC rooms being struck by lightning, a very bad consequences will be caused. Generally IDC rooms will not suffer from the harm of lightning, but lightning can produce interference to equipments inside the computer room In the form of electromagnetic radiation, the over voltage and the over current wave along the wire [2].whether can effectively reduce the interference above mentioned is the only way to judge the lightning protection measures of IDC Room. Inhibition of lightning electromagnetic radiation, stopping the invasion of the induced overvoltage and over current wave, evacuation of lightning current into the earth are all the works for lightning protection of IDC rooms. so the key parameters should include these abilities of the lightning protection system [3]. To explain the key parameters more clearly, this article take a practical engineering as an example to discuss. The room area is 2600 square meters with 500 cabinets in this room. The equipment brands are mainly Cisco and Huawei. The height of the room is 3.6 meters. The IDC require the 10/350 us waveform, and the lightning current largest i0 is $150 \mathrm{kA}$. The output residual voltage of the SPD at the end of the power is $600 \mathrm{~V}$, and $400 \mathrm{~V}$ output residual voltage is for signal circuits [4]. The IDC adopts independent lightning protection system. The center room uses dual high-voltage grid stable power supply and dual redundancy $(1+1)$ UPS for power supply. So dual power supply and automatic switching is realized. The IDC room adopts underfloor air supply, and the air supply of the power room is from the upper direction to accurately control the temperature and humidity of the room space.

\section{The Space Shielding Effectiveness}

The space shielding effectiveness is the attenuation of electromagnetic radiation intensity in the room after taking shielding measures to the computer room space. Because the grid size of the steel structure frame of the building is bigger than $5 \mathrm{~m} \times 5 \mathrm{~m}$, its primary shielding effectiveness is small enough to be ignored. So for the lightning electromagnetic environment partition, the equipments in the room should be calculated at in LPZ1 area. Under the condition of the safety distance requirements, the shielding factor of LPZ1 area is [5]: 


$$
\begin{aligned}
& S F=20 \lg \left[(8.5 / \mathrm{w}) /\left(1+18 \times 10^{-6} r^{2}\right)^{1 / 2}\right] \\
& \mathrm{W}=1 \mathrm{~m} 、 \mathrm{r}=0.06 \mathrm{~m}, \quad \mathrm{SF} \approx 18.59 \mathrm{db} . \\
& H_{0}=i_{0} / 2 \mathrm{r} \mathrm{s}=23885 / \mathrm{s}
\end{aligned}
$$

$\mathrm{i}_{0}=150 \mathrm{KA}, \mathrm{s}$ is for the distance from the calculating point to the lightning strike point (The unit is m);

When the lightning strike point is at outside the building, relating to the field intensity H0 in no shielding area, the magnetic field strength attenuation in shielding room is according to the type (3).

$$
H_{1}=H_{0} / 10^{\mathrm{sf} / 20}
$$

After calculating the $\mathrm{H} 1$ meets the requirements of IDC rooms

For this IDC room, after taking the measure of the grid shielding, there is no threat from the near lightning electromagnetic radiation. So we consider a serious condition, assuming that a flash of lightning directly strike on the lightning conductor of the building, Under the condition of the safety distance requirements, $\mathrm{H} 1$ should be the following type [6]:

$$
H_{1}=K_{H} i_{0} w /\left(d_{w} d_{r}^{1 / 2}\right)
$$

In the formula:

$\mathrm{K}_{\mathrm{H}}$ is for the shape factor, $\mathrm{K}_{\mathrm{H}}=0.01$ (unit: $1 / \mathrm{M} 1 / 2$ );

$\mathrm{i}_{0}$ is for lightning current. The first time struck for the second class lightning protection building is $150 \mathrm{ka}$ according to the specifications;

$\mathrm{W}$ is for shielding grid width; $\mathrm{d}_{\mathrm{w}}$ is for the minimum distance from calculating point to the shielding wall; $d_{r}$ is for the minimum distance from calculating point to the shielding top.

The minimum distance from the equipment to the wall is $2 \mathrm{~m}$ in the IDC room. For the equipment, $d_{w}$ is $2 \mathrm{~m}$. The minimum distance from the equipment to the shielding top is also about $D_{r}=2 \mathrm{~m}$. So in this environment, the biggest magnetic field strength is:

$$
\mathrm{H} \max =0.01 \times 150000 \times 1 /(2 \times 1.41) \approx 530
$$

After calculating the $\mathrm{H}$ max meets the requirements of IDC rooms.

\section{The Cable Shielding effectiveness}

The Distance between the Down Lead and the Cables. On the condition of the lightning striking at the buildings, in order to prevent electronic equipment in the building from the instantaneous high voltage counter strike caused by lightning current flows through down lead and grounding device, when the power cables and signal cables do not connected to the lightning protection grounding device, the cables should be a certain distance apart with the down lead Sa3 [7]. According to the nature of its use and the importance, This system belongs to the second class lightning protection.

当 $\mathrm{L}_{\mathrm{x}}<5 \mathrm{Ri}$ 时, $\mathrm{S}_{\mathrm{a} 3} \geq 0.3 \mathrm{~K}_{\mathrm{c}}\left(\mathrm{R}_{\mathrm{i}}+0.1 \mathrm{~L}_{\mathrm{x}}\right)$ 。

When the $\mathrm{L}_{\mathrm{x}}<5 \mathrm{R}_{\mathrm{i}}, \mathrm{S}_{\mathrm{a} 3} \geq 0.3 \mathrm{kc}\left(\mathrm{R}_{\mathrm{i}}+0.1 \mathrm{~L}_{\mathrm{x}}\right)$.

In the formula: $S_{a 3}$ is for the distance in air, $\mathrm{m}$;

$\mathrm{R}_{\mathrm{i}}$-The impact grounding resistance, $\Omega$;

$\mathrm{L}_{\mathrm{x}}$-The distance from the calculating point of down lead to the ground, $\mathrm{m}=8 \mathrm{~m}$;

$\mathrm{K}_{\mathrm{c}} \longrightarrow$ Divider coefficient $[1,5-6], \mathrm{K}_{\mathrm{c}}=0.66$ 。

The impact grounding resistance $\mathrm{R}_{\mathrm{i}}=\mathrm{R} \sim / \mathrm{A}(\Omega)$, In the formula, Conversion factor $\mathrm{A}=1.5$. The $R_{i}=1 / 1.5=0.66 \Omega$. So the distance from the power cables or signal cables to the down lead is:

$$
\mathrm{S}_{\mathrm{a} 3}=0.3 \times 0.66 \times(0.66+0.1 \times 8)=0.29 \mathrm{~m}
$$


After calculating the $S_{\mathrm{a} 3}$ meets the requirements of IDC rooms.

The Transient High Voltage. $U$ is the transient voltage on arbitrary point of the down lead outside the room. U calculated according to the formula:

$$
U=I R_{\mathrm{i}}+L_{0} 1_{x}\left(d_{i} / d_{t}\right) \quad(k V)
$$

In the formula: I is for the amplitude lightning current, $\mathrm{I}=100 \mathrm{kA}$;

$d_{i} / d_{t}$ is for the gradient of lightning current, $I / T_{1}=100 / 10=10 \mathrm{kA} / \mu \mathrm{s} （ T_{1}$ is for front time $\left./ \mu \mathrm{s}\right)$.

$\mathrm{L}_{0}$ is for parasitic inductance per unit length of down lead, $\mathrm{L} 0=1.55 \mu \mathrm{H} / \mathrm{m}$.

The transient high voltage between the calculation point of down lead at the switch location and the location of $6.5 \mathrm{~m}$ relative to the ground, $\mathrm{U}^{[8]}$ :

$$
\mathrm{U}=100 \times 3.9+1.55 \times 6.5 \times 10=490.75 \mathrm{kV}
$$

\section{Limits of Terminal Maximum Pulse Voltage}

The pulse voltage of equipments in IDC room is the sum of the output of the SPD residual voltage at the last stage and the voltage of both ends of the SPD wires. For the last stage SPD, the maximum pulse voltage is:

$$
\zeta=U+L d_{i} / d_{t}
$$

In the formula: $\mathrm{d} \mathrm{i} / \mathrm{d} \mathrm{t}$ is for the gradient the pulse current ahead of the last stage SPD. After first 3 level SPD and before the final stage of the SPD conduction ${ }^{[9]}$, limiting voltage Up= $1500 \mathrm{~V}$.According to $10 / 350 \mu \mathrm{s}$ waveform, the front time $\mathrm{T}=10 \mu \mathrm{s}$. The wires distance between the second and the third stage SPD is roughly $10 \mathrm{~m}$.When wires inductance is calculated at $1 \mu \mathrm{H}$ per meter, the inductor between wires of the two stage of SPD is $10 \mu \mathrm{H}$. The amplitude of the pulse transient current:

$$
\mathrm{i}_{0}=\mathrm{U}_{\mathrm{P}}(\mathrm{T} / \mathrm{L})=1500 \times 1=1500 \mathrm{~A}
$$

So $\mathrm{d}_{\mathrm{i}} / \mathrm{d}_{\mathrm{t}}=1500 \mathrm{~A} / 10 \mu \mathrm{s}$. UC is for the residual pressure parameters of last stage SPD. According to the above mentioned in this case $\mathrm{UC}=600 \mathrm{~V} ; \mathrm{L}$ is for the wires inductance of both ends of SPD. The length of the wire is 1 meter. $\mathrm{L}$ is $1 \mu \mathrm{H}$. $\mathrm{U}_{\mathrm{C}}=600+150=750 \mathrm{~V}$. In addition, the residual voltage of the signal SPD is $400 \mathrm{~V}$, so the maximum pulse over the equipment is $550 \mathrm{~V}$.

\section{The Induced Voltage of the Biggest Split Ring of IDC Room Cabling}

The biggest split ring of IDC room cabling is to find out the biggest loop of the whole cables surrounded in the room, including power supply, signal, and grounding cables. For this example, all kinds of cables are complete shielding before entering the cable racks. Because the shielding tubes, the cable racks, and the ground wires are connected together with the grounding terminals, the biggest loop is chose from the loop of different cables routes through the shielding tubes. The maximum length of power supply cables or signal cables without shielding is nearly $3 \mathrm{~m}$, and the width is nearly $0.5 \mathrm{~m}$. This example assumes the most extreme case, so the calculation focuses on the subsequent lightning strike ${ }^{[10]}$.

$$
U_{0 c / \max }=\mu_{\mathrm{c}} b \ln \left(1+l / d_{w}\right) K_{H}\left(\mathrm{w} / d r^{1 / 2} i_{0 / \text { max }} / T\right)
$$

In the formula: $\mathrm{U}_{0}=4 \pi 10^{-7}$ (Coefficient of magnetic conductivity of vacuum), $\mathrm{K}_{\mathrm{H}}=0.01$ (Shape factor);

$\mathrm{I}_{0 / \max }=37.5 \mathrm{~A}$ (Maximum value of lightning current of the second types of lightning protection building)

$\mathrm{d}_{\mathrm{w}}$ : The minimum distance from the equipment to the wall is $2 \mathrm{~m}$

$\mathrm{D}_{\mathrm{r}}$ : The minimum distance from the equipment to the shielding top is $2 \mathrm{~m}$. 


\section{The Capacity of Voltage Balancing and Discharge}

All the effectiveness talked above ultimately rely on the grounding system. The smaller the grounding resistance value is, the better the effects will be have. But because thunder lightning interference belongs to the transient pulse current, the inductive reactance of the conductor has a great influence on discharge. To the different points of the same grounding resistance, the impedance is different because the different wire length and materials[11].Therefore, for the security of the computer room, only to achieve steady state voltage is not enough, but also to consider the transient ground potential equilibrium, which is more important. Only the electrical connection cannot solve the potential problem, the grounding should also to be tried to make the grounding wire impedance. The inductance of a certain wire diameter is mainly determined by the length of the wire, and also depends on the distance from the reference point.

\section{Concluding}

IDC is the infrastructure of various modes of e-commerce, and its safe operation is related to network security in the region. This paper analyzed and obtained the key parameters which Influence on the reliability of the lightning protection system reliability of IDC rooms. The key parameters include the space shielding effectiveness and the transmission cable shielding effectiveness, the maximum pulse voltage limits for terminals, the induced voltage of the biggest split ring of IDC room cabling, the voltage balancing and the discharge capacity, etc. The key parameters are calculated to obtain the feasible implementation plan. It is expected to provide technical reference of lightning protection for this kind of IDC room.

\section{Reference}

[1] Mu Jiaxiao, Lightning fault case analysis of large scale IDC data room and integrated terminal communication buildings, Guangdong Communication Technology(2015)

[2] Yang Youqi, Electrical safety engineering, Capital University of Economics and Business press, Beijing, 2000

[3] Zhang Xiaoqiing, Lightning protection of electronic equipment in building, Beijing, Electronic Industry Publishing House(2002)

[4] GB50343-2012, Technical code for building electronic information system against lightning (2012)

[5] GB50057-2010, Design code for protection of Structures against lightning(2010)

[6] J .zhang, Magnetic field intensity analysis in lightning protection zone of elevator machine room for high-rise buildings and defense technology, Meteorological Science and Technology.5 (2014) 918-921.

[7] X.H.Zhu, Protective measures for high potential strike back caused by lightning current flows through the down conductor in buildings[J].Journal of Meteorological Research and Application.7(2015)36-38.

[8] Zhou Fengyun, The lightning induction defense for internal building, Journal of Shandong Meteorology.7(2004)39-40

[9] Hong Bin, The application of SPD in lightning protection design for Jinshan garden information system.6(2006)45-49

[10]Jiang Anfeng, The influence of subsequent lightning to $10 \mathrm{kV}$ power distribution lines and lightning protection measures, Power System Technology.6(2016)38-44。 
[11] Mo Yun, The research of impact characteristic of grounding device for $10 \mathrm{kv}$ distribution circuit based on PSCAD, Insulators and Surge Arresters.3(2013)53-58. 